\title{
Uma história erótica e literária do cinema latino-americano
}

\author{
Helder Thiago Maia \\ Universidade de São Paulo/FAPESP
}

Resumo: Nesse artigo, a partir de textos literários latino-americanos em diferentes gêneros textuais, especialmente cubanos, chilenos, argentinos e brasileiros, tentamos reconstruir a história do cinema e a história do erotismo nas salas de exibição cinematográfica. Assim, através do diálogo entre história e literatura, abordamos as primeiras exibições cinematográficas e chegamos aos cinemas pornográficos e às salas multiplex.

Palavras-chave: História do Cinema, Erotismo, Literatura

Abstract: In this article, from Latin American literary texts in different textual genres, especially Cubans, Chileans, Argentines and Brazilian, we try to reconstruct the history of cinema and the history of eroticism in the movie theaters. Through the dialogue between history and literature, we approached the first cinematographic exhibitions and arrived at the pornography theaters and the multiplex rooms.

Keywords: History of Cinema, Eroticism, Literature 
O espaço físico onde habita o cinema mudou histórica e espacialmente de acordo não só com as inovações técnicas e a consequente industrialização, mas também em sintonia com os novos hábitos de consumo, com os novos códigos de moralidade e com as transformações das cidades. Dos "simples" jogos ópticos do início do século XIX a um importante dispositivo de construção de identidades nacionais, étnicas, sexuais do século $\mathrm{XX}$, o cinema forjou uma maneira de apreciá-lo que encontrou na arquitetura, talvez, o seu mais importante aliado. Assim, se existe uma "situação cinema", como afirma Barthes (2009: 350), mais do que a narrativa fílmica, importaria a arquitetura e a escuridão.

Entretanto, enquanto sabemos e investigamos ininterruptamente como as narrativas e as técnicas cinematográficas funcionam como tecnologias de gênero e sexualidade (Lauretis 1994), pouquíssimos estudos se debruçaram sobre o outro lado da situação cinema: o espaço de exibição. Procuramos, portanto, com este trabalho, entender como o espaço físico cinematográfico funciona tanto como uma tecnologia de gênero e sexualidade quanto como um dispositivo biopolítico. Nesse sentido, as constantes intervenções governamentais não só sobre as narrativas fílmicas - o que inclui a censura, o controle por faixa etária, as propagandas de governo, etc. -, mas principalmente sobre o espaço físico - o que inclui quais corpos podem frequentar ou não determinadas salas, como e onde estas salsa podem funcionar, etc. - são um importante desdobramento dos saberes-poderes que atravessam a "situação cinema".

\section{Uma história sobre o escuro}

As feiras de variedades, parques, praças, circos, galpões, bares, salões e cabarés fazem parte, principalmente, da "primeira fase do cinema". A partir de Costa (2005: 34), usamos essa expressão para nos referirmos aos anos que compreendem tanto um período não narrativo (1894-1908), quanto um de narratividade crescente (1908-1915).

No período não narrativo, marcado por exibições ambulantes e esporádicas, o público era atraído pelas ilusões de óptica e pelas novidades tecnológicas; o cinema, segundo Bessa (2013: 45), não passava de uma curiosidade científico-tecnológica. No período de narratividade crescente, as exibições passam a ocorrer em pequenas salas e 
teatros. Como explica Pena (2013: 15), era inviável a abertura de salas específicas para a exibição cinematográfica, uma vez que os filmes ainda eram muito curtos, não ultrapassando cinco minutos, por isso, as sessões eram realizadas em espaços onde também se comia, bebia, conversava e dançava.

É necessário dizer que a sensualidade, o erotismo e/ou a pornografia já estavam presentes desde o período não narrativo nas exibições cinematográficas. Como assegura Abreu (1994: 26), desde os primeiros cinematógrafos, o "público masculino" podia assistir a mulheres semidesnudas ou em trajes de banho em movimentos sensuais e lascivos. Nesse mesmo sentido, um público interessado no corpo masculino podia assistir ao fisiculturista Eugen Sandow exibir seus músculos em trajes mínimos, no filme Sandow: the strongman (1894).

Entre 1915 e 1916, o poeta e ensaísta mexicano Alfonso Reyes (1995) publicou cerca de trinta e nove textos, em dois jornais madrilenhos, España e El imparcial, sob o pseudônimo Fosforo, que nos ajudam a reconstruir essa primeira fase do cinema. Entre análises de filmes exibidos em forma de folhetim, comparações entre a narrativa literária e a cinematográfica e queixas à sonorização, à legendagem e à qualidade do negativo dos filmes, Reyes afirma, em 28 de outubro de 1915, que foi a indústria que salvou o cinema de ser apenas um passatempo fugitivo que logo seria esquecido. Em outros textos, o autor descreve também o surgimento dos better films e dos moving pictures, filmes "purificados" para crianças e adolescentes, assim como também noticia uma investigação sobre a moralidade nos estúdios de gravação, o que indica que a suspeita de imoralidade sobre o cinema recaía também sobre produtores, atores e atrizes.

A afluência do público ao espetáculo cinematográfico cresceu, em consequência, aumentaram também as preocupações com a insalubridade das novas salas, assim como com questões morais. Por conta disso, sobre as novas salas passaram a atuar dispositivos cujas preocupações sanitárias não deixavam de ser também moralizadoras. Ao perigo epidemiológico oferecido pela grande concentração de pessoas em locais abafados e fechados, somava-se o medo provocado pela necessária escuridão das salas. Ao escuro estavam associadas não somente questões de insegurança, mas principalmente suspeitas de 
imoralidade. Por ser o escuro entendido como "a cor de um erotismo difuso", como afiança Barthes (2009: 351), rapidamente o cinema foi também percebido como um lugar de intensa disponibilidade erótica. Por conta disso, foram tomadas algumas medidas para evitar que esses espaços se tornassem uma ameaça à ordem e à moral coletiva, uma vez que a escuridão era uma necessidade técnica da exibição cinematográfica.

No livro La Habana para un Infante difunto (1979[2005]), o escritor cubano Guillermo Cabrera Infante nos apresenta os "perigos" e os prazeres do escuro dos cinemas cubanos. Nestes, o narrador conhece tanto as suas primeiras paixões platônicas, quanto descobre a hetero e a homossexualidade. 0 narrador, que a princípio poderia ser tomado, desde que fosse uma mulher, como o principal alvo dos dispositivos moralizadores que atravessam o cinema, conta-nos, por exemplo, como sua sexualidade se deslocou da claridade das ruas para o escuro do cinema.

lo que hizo que mi amor trompero se desplazara definitivamente de las calles soleadas o desoladas a las salas oscuras (casi siempre iba al cine de tarde y la oscuridad formaba cavernas platónicas) del cine para interferir, con mi pasión por el cine, la realidad de la carne desvelándome del sueño del cine. (Cabrera Infante 2005: 53)

Assim sendo, uma das primeiras interdições que recaem sobre as salas de cinema é a restrição relacionada à presença de mulheres desacompanhadas. A mulher foi privada da escuridão oferecida pelo cinema, que se não lhe permitia passar algumas horas "sem controle", como sugere Adorno (1985: 114), ao menos lhe permitia passar algumas horas longe de alguns dispositivos de controle, ainda que os filmes estivessem quase sempre destinados a docilizá-la.

O conto "A solidão de Acácio", de Alcides Pinto, presente em uma das primeiras antologias brasileiras com personagens dissidentes de gênero e/ou sexualidade, Histórias de Amor Maldito (1967), organizada por Gasparino Damata, reescreve essa interdição sobre o corpo da mulher a partir da interdição do corpo da travesti Rubiana. No conto, Rubi é proibida pelo companheiro, o tenente Guilherme, sob qualquer hipótese, de ir ao cinema. Dessa forma, o acesso a filmes, que era uma parte importante da vida da personagem, 
deveria ser feito somente através da televisão. "Nem sonhe de ir ao cinema, assista filmes na televisão" (Damata 1967: 26), diz o amante. No que se refere à circulação pública de Rubiana, podemos dizer que a relação entre os dois se organiza a partir de interdições sexistas e heteronormativas, que apesar de serem tradicionalmente impostas às mulheres cisgêneras, não deixam também de interpelar violentamente corpos dissidentes.

O narrador de Cabrera Infante (1979), que recorda a sua infância e adolescência em Havana, além da sua aprendizagem sexual no escuro das salas de cinemas, entre os anos 40 e 60, observa como "uma nova moral sexual" pode ser percebida no país justamente a partir do comportamento das mulheres nos cinemas. Assim, o crescente número de mulheres desacompanhadas nos cinemas seria um indício de que elas estariam resistindo e recusando o papel submisso a que estavam condenadas pela moral cubana.

Quanto à recepção cinematográfica pela televisão, podemos dizer que não há fascinação nessa exibição, uma vez que, como recorda Barthes (2009: 352), não só está eliminado a escuridão e o anonimato das salas de cinema, como também praticamente não há imobilidade e silêncio. Na televisão experimentamos, portanto, um espaço domesticado que elimina o erotismo e nos condena à moral familiar. Consequentemente, se a moral da época condenava a mulher, especialmente a não proletária, ao ambiente familiar, a interdição sobre o cinema era mais um desdobramento de outras interdições às quais as mulheres estavam sujeitas no espaço público.

$\mathrm{Na}$ novela 2666 (2004), do chileno Roberto Bolaño, podemos inferir uma interessante comparação entre o espectador do cinema e o telespectador. No livro, o jornalista norte-americano Fate vai à cidade de Santa Teresa, inspirada em Ciudad Juárez, cidade mexicana que ficou conhecida pelos altos índices de feminicídio, para cobrir uma luta de boxe para uma revista do Harlem, que se dedica, principalmente, às questões raciais. Após a luta entre Count Pickett e Merolino Fernández, Fate vai a um restaurante com amigos. Enquanto jantam, Charly fala com Fate sobre cinema: sobre um diretor conhecido de Charly e desconhecido por Fate, sobre o surgimento dos dvds, o desaparecimento das grandes salas de cinema e finalmente sobre a experiência de assistir filmes na televisão. $\mathrm{Na}$ perspectiva de Charly, a televisão, a depender do cumprimento de alguns requisitos por 
parte do telespectador, pode se aproximar, ainda que minimamente, da experiência do espectador de cinema. Entretanto, como perceberemos, esses requisitos são difíceis de serem alcançados na experiência cinematográfica doméstica.

Un televisor no es lo mismo que una pantalla de cine. La sala de tu casa no es lo mismo que una vieja platea casi infinita. Pero, si uno observa con cuidado, es lo que más se le parece. [...] Primer requisito: estar solo. La casa puede ser grande o pequeña, pero si no hay nadie más toda casa, por pequeña que sea, de alguna manera se agranda. Segundo requisito: preparar el momento, es decir, alquilar la película, comprar la bebida que vas a beber, la botana que vas a comer, determinar la hora en que te vas a sentar delante de tu tele. Tercer requisito: no contestar al teléfono, ignorar el timbre de la puerta, estar dispuesto a pasar una hora y media o dos horas o una hora o cuarentaicinco minutos en la más completa y rigurosa soledad. Cuarto requisito: tener a mano el mando a distancia por si quieres ver más de una vez una escena. Y eso es todo. A partir de ese momento todo depende de la película y de ti. Si todo va bien, que no siempre va bien, uno está otra vez en presencia de lo sagrado. (Bolaño 2004: 398)

Apesar disto, a interdição mais facilmente naturalizada, sendo rapidamente desejada como parte da "situação cinema", foi a figura do lanterninha. Surgidos, ainda nos anos 20, em um momento de construção das grandes salas, os lanterninhas circulavam, como recorda Câmara Vale (2000: 48), empenhados na manutenção da ordem e da moralidade no interior das salas. Assim como o projeto da modernidade é o projeto do olhar e da vigilância, os lanterninhas são os olhos, os dispositivos disciplinares, o panóptico, no escuro dos cinemas; suas pequenas luzes disciplinares funcionam como a lei, a norma, a interdição, a razão e a moralidade moderna.

No conto "Paraíba" (1975), do brasileiro Damata, podemos perceber como a luz funciona como um dispositivo disciplinador e moralizador. A história nos apresenta um diálogo entre o narrador, um fiscal de obras, e um atendente de lanchonete; dois homens cisgêneros, garotos de programa, pernambucanos, que vivem no Rio de Janeiro. A narrativa, apesar de uma linguagem que parece não acompanhar a origem e o meio social dos personagens, constrói em torno desses dois homens, não somente a figura do michê que não se entende como homossexual, mas principalmente a ideia da cultura nordestina como 
lugar de atraso, enquanto a cultura carioca é entendida como mais moderna e menos preconceituosa.

No texto, a luz aparece em dois momentos. No primeiro, as luzes do cinema são acesas quando há um princípio de confusão dentro da sala. A luz, portanto, funciona para controlar e reestabelecer uma ordem dentro do cinema, mesmo que mais permissiva. São os gritos de um cliente, que desconhecia os usos eróticos dentro daquela sala, e, por este motivo, reclamava da presença de homens fazendo sexo nas poltronas, que fazem as luzes serem acesas. Em um segundo momento, aborda-se a presença do lanterninha dentro do cinema, onde os usos eróticos, ainda que controlados, são mais permissivos. 0 texto aponta, então, para um afrouxamento das suas funções disciplinadoras. Por isso, o narrador, provavelmente acostumado à presença moralizadora dos lanterninhas em outras salas, após algumas visitas a este cinema pornográfico, afirma ter começado a notar que "o pessoal não se importava com o lanterninha, nem com o guarda, e que a sacanagem lá em cima corria rasgada" (Damata 1975: 10). Deslocando-se, portanto, os usos do cinema, altera-se ou precariza-se também as funções disciplinadoras dos lanterninhas.

No jornal Lampião da Esquina, primeiro jornal lgbt brasileiro de circulação nacional, na edição de novembro de 1980, sabemos, a partir de depoimentos de frequentadores do Cine Íris, o mais antigo cinema brasileiro em funcionamento, que lanterninhas, juntamente com policiais e outros achacadores, estavam perseguindo e chantageando as "bichas". No mesmo jornal, na edição de maio de 1981, além da denúncia de espectadores de abuso policial nesses espaços, o delegado José Gomes de Andrade nos informa que as constantes batidas policiais no Íris foram solicitadas pela proprietária do espaço. É importante ressaltar a colaboração do mercado à repressão de gênero e sexualidade para percebermos que essas ocupações eróticas do cinema não se deram a partir de um desejo do mercado de sobreviver à falência dos cinemas de rua, mas sim a partir de um uso que resistiu à própria repressão do mercado e da polícia.

Um dos poucos textos literários a abordar o roubo e a chantagem dentro dos cinemas é La calle de los caballos muertos (1982), do argentino Jorge Asís, que é narrado por Sandro e conta a sua história e a de outros dois primos tucumanos, habitantes de uma 
favela da grande Buenos Aires. Em uma dessas histórias, Sandro relata como Ramón costumava sair e transar com homossexuais, seja no cine Colonial, seja na casa de homens que conhecia no circuito de deriva homossexual. Esses encontros, entretanto, quase sempre terminavam em extorsão e espancamento.

Por su parte, el Ramón fue, de movida, un ratero. [...] Especialmente los sábados, salía de noche a caminar por Lavalle, la del centro, desde Pellegrini hasta Florida, lentamente iba y volvía, miraba. 0 las noches de viernes por la avenida Mitre, de Avellaneda, desde la plaza hasta Pavón, se paraba en la puerta del cine Colonial. Miraba, lúdicamente, a los maricas, se hacía perseguir, se hacía levantar, en el Colonial se la hacía chupar. Si podía, claro, después los desvalijaba, amenazaba con hacerles un desastre en el departamento, con denunciarlos por intento de corrupción, les pegaba. [...] El Ramón decía que no, pero, seguramente, antes de robarles o pegarles, los penetraba. (Asís 1982: 18-19)

Ainda sobre lanterninhas, na novela Cinema Orly (1999), de Luís Capucho, cuja narrativa se passa na década de 80, o narrador relata que no cinema Orly os lanterninhas pareciam ter apenas uma presença decorativa, já que não interferiam em nenhuma das atividades eróticas que se experimentava no local, como nos conta o narrador:

Fumávamos, chupávamos pau e dávamos o cu a despeito do lanterninha que fingia nada ver [...] Era um trabalho meio que apenas para afirmar que o cinema tinha seu lanterninha [...] nenhuma atividade sexual era repreendida e o lanterninha era apenas mais um objeto do nosso desejo. (Capucho 1999: 27)

Nesse mesmo sentido, na crônica "Baba de caracol en terciopelo negro" (2001), que retrata o cinema Nagasaki, da Plaza de Armas, em Santiago, Pedro Lemebel diz que o lanterninha trabalha apenas por rotina, atuando sem atrapalhar demasiadamente as cenas eróticas que se passam entre a plateia, uma vez que ele sabe que ninguém está ali para ver o filme exibido.

No conto "Cine Privê" (2009), de Antônio Carlos Viana, conhecemos a história do antigo lanterninha, "seu Manuel", que com a obsolescência da sua antiga função passou a trabalhar como auxiliar de limpeza. Em diálogo com o dono do cinema, "seu Gamaliel", 
podemos perceber como as regras de moralidade são afrouxadas, ainda que o discurso oficial de controle dos usos eróticos no cinema afirme o contrário. Diz o narrador:

De todos os cines privês, o de seu Gamaliel tem fama de ser o mais limpo, o de maior respeito, não é lugar de pegação. Seu Manuel faz muxoxo, tudo jogo de cena, porque nos tabiques que separam as cabines tem uns buracos pra ventilação que ele sabe muito bem para que servem. (Viana 2009: 160)

Nos cinemas não-pornográficos, a figura do lanterninha também tende a desaparecer. Nas novas salas de cinema multiplex, duas intervenções parecem ter facilitado o desaparecimento desses trabalhadores: a colocação de luzes indicadoras no piso das salas, o que afeta a escuridão e o erotismo sem prejudicar a projeção, e o acesso ao mapa do cinema na compra dos ingressos. Além disso, a precarização dos trabalhadores do cinema, que passaram a exercer mais de uma função, significou também uma grande economia para os empresários do ramo. Entretanto, parece-nos também que a (desejada) vigilância, inicialmente exercida pelos lanterninhas, foi fortemente incorporada pelos próprios espectadores. Desse modo, a intervenção de algum funcionário do cinema, sobre alguma prática não tolerada, pode ser feita, quando acionados, por seguranças, que costumam ficar fora das salas.

O primeiro controle das condutas permitidas dentro da sala de exibição é, portanto, delegada e exercida pelos próprios espectadores. Concordando com Cortés (2008: 10), podemos dizer que houve uma forte internalização dos imperativos disciplinares, especialmente, nas salas multiplex. Uma vigilância, convém lembrar, que começa com as câmeras de segurança nos arredores desses locais e se intensifica nas portas de acesso das salas, que estão quase sempre localizadas em shoppings, igualmente vigiados e controlados.

Como já dissemos, o erotismo e/ou a pornografia faz parte da narrativa fílmica desde os primeiros experimentos ópticos. Assim sendo, podemos afirmar que os cinemas pornôs, enquanto espaços físicos de usos eróticos, também têm sua origem na primeira fase do cinema com a exibição dos stag films. Os stag films eram, principalmente, filmes norteamericanos e franceses mudos, preto e branco, com poucos minutos, que eram exibidos, de acordo com Preciado (2010: 54), em espaços domésticos ou privados para uma plateia 
exclusivamente masculina e com bom poder aquisitivo. Segundo Pena (2013: 17), esses filmes circulavam ilegalmente não só em bordéis, mas também em salas de exibição em horários noturnos especiais, com a finalidade de driblar a proibição a que estavam submetidos.

Um dos objetivos desses filmes, que é o mesmo dos que são atualmente exibidos em cinemas pornôs, era não só excitar, mas também incitar sexualmente aos espectadores, por isso, muitas vezes, eram exibidos em locais de maior permissividade sexual. Podemos afirmar também que os stag films, conforme Pena (2013: 72), não tinham grande continuidade narrativa e muitas vezes eram compostos apenas de atos sexuais. Os mais antigos stag films dos quais se têm notícias são o argentino El Sartorio, produzido em 1907, o francês L'Ecu d'Or ou la bonne auberge, de 1908, e o alemão Am Abend, de 1910. Segundo Abreu (1994: 31), a produção de stag films se estendeu até o início dos anos 60 conservando, devido a sua proibição, as formas primitivas originais, mesmo quando o cinema já havia incorporado som, cor e produções mais longas.

À parte esses espaços e projeções clandestinas, podemos afirmar que o cinema sempre foi um local de encontro para os dissidentes sexuais, ainda que nem sempre tenha sido um espaço de maior permissividade sexual. Nesse sentido, os contos "O menino do Gouveia" (1914), assinado sob o pseudônimo de Capadócio Maluco, e "La narración de la historia" (1959), do argentino Carlos Correas, nos narram os usos que alguns homens faziam do espaço cinematográfico, antes mesmo deles se tornarem efetivamente pornográficos.

"O menino do Gouveia", que é considerado a segunda mais antiga narrativa de temática homoerótica brasileira, foi publicado pela editora do jornal $O$ Rio $\mathrm{Nu}$. $\mathrm{O}$ conto é narrado tanto por Capadócio Maluco, quanto por Bembem, que é o menino do Gouveia. Gouveia ou Gouvêa é um termo amplamente utilizado pelo jornal que se refere tanto ao homem heterossexual interessado em sexo anal com mulheres quanto ao homossexual ativo que se interessa por rapazes mais jovens e costuma frequentar o Largo do Rocio (atual Praça Tiradentes, no Rio de Janeiro).

A narrativa, que está dividida em quatro partes, conta-nos, principalmente, a vida de 
Bembem. Dessa forma, o "menino", enquanto masturba Capadócio, relata-nos como se tornou um "puto matriculado". Conhecemos, assim, os desejos eróticos, a tentativa de sedução e a expulsão de casa de Bembem, assim como o encontro com o primeiro amante, o Gouveia, no Largo do Rocio. É o Gouveia que leva Bembem ao cinema, onde o "menino" assiste a toda sessão "segurando-lhe a pica" (Maluco 1914: 10), como podemos ver nesse trecho:

O meu novo camarada pareceu ficar mais moço, convidou-me para ir ao cinema, onde assisti a uma sessão inteira segurando-lhe a pica. Depois, quando sahímos, eu e seu Gouveia, era assim que elle se chamava, fomos tomar chocolate com pão de ló. Finalmente, às dez horas, mais ou menos, eu, com o braço do meu novo amigo passando pela cintura, entrava no quarto em que elle morava, ali pelas bandas dos Arcos [...] 0 Gouveia era um hábil fanchono e possuía a verdadeira arte de um amador de cús. (Maluco 1914: 10)

Em La narración de la historia, o personagem Ernesto vai ao Cine Colonial, em Avellaneda, depois de ficar "perturbado" com a notícia do casamento de um ator. 0 cinema se apresenta como um lugar de flerte, onde Ernesto escolhe sentar-se sempre ao lado de jovens que deseja abordar; para isso, roça a perna nos seus alvos, com o intuito de tentar algum tipo de contato erótico. Diante do fracasso da sua abordagem, Ernesto vai para a estação de trens de Constituição, local conhecido pela grande presença de homossexuais, onde termina conhecendo o chongo $^{1}$ Juan Carlos Crespo. Um rapaz de dezessete anos com quem se envolve.

Poderíamos dizer que a diferença de classe contribuiu para a decisão de Ernesto de se afastar de Juan no final do conto, uma vez que Ernesto em vários momentos sente vergonha de ser visto com Juan, um rapaz de mãos sujas, vestido de jeans e casaco de couro amarelo, que dormia na casa de amigos ou até mesmo na rua, enquanto Ernesto, que fazia faculdade e morava com a família, estava sempre de terno, gravata e chapéu. Também poderíamos afirmar que a repressão familiar era outro elemento que afastava os dois personagens. Juan, órfão de um pai ausente e alcoólatra, foi criado longe das pressões familiares. Por conta disso, Ernesto invejava a liberdade "graciosa y arbitraria" de Juan, já 
que tinha sido criado por um pai severo, que o obrigava a casar e ter filhos para manter a "dinastia" da sua família de imigrantes.

Entretanto, parece-nos mais provável, seguindo não só as pistas que o próprio texto fornece, mas também a um comentário do autor (Peralta 2013: 444), que a principal incompatibilidade entre os dois refere-se tanto às práticas sexuais, dado que ambos são descritos como ativos, quanto a uma disputa em torno da masculinidade e do medo da feminilização. Ambos temem, portanto, serem lidos socialmente como invertidos, ou melhor, como passivos e afeminados, já que Juan é entendido como um chongo, enquanto Ernesto se entende como um pederasta que em um futuro distante dos seus atuais vinte e dois anos se casaria com uma "muchacha flaca y casi sin pechos que se dejara poseer con indiferencia" (Correas 1959: 7).

Interações eróticas em cinemas não pornográficos, tanto entre dissidentes, como entre casais heterossexuais, aparecem em Mário Donato (1948), no livro Presença de Anita, que narra encontros eróticos entre Anita, descrita como uma adolescente solteira, sedutora e fantasmagórica, e Eduardo, descrito como um homem casado, introvertido e mais velho, assim como em Jorge Jaime (1953), na parte confessional de Homossexualismo masculino, como podemos perceber neste trecho em que o narrador relata o seu encontro com Ricardo, um amigo de São Paulo: "Lá dentro, na escuridão da sala, minha perna de leve roçagou as suas pernas. Estranho torpor me foi dominando e aos poucos percebi-me entontecido por suas caricias. Quase não vi o filme que se desenrolava na tela" (Jaime 1953: 56).

Isto posto, cabe-nos afirmar que, ainda hoje, o cinema é um espaço onde dissidentes de gênero e sexualidade, mas não somente estes, sociabilizam e jogam eroticamente. No romance No se lo digas a nadie (1994), do jornalista peruano Jaime Bayly, podemos perceber, por exemplo, algumas dessas experiências eróticas em cinemas mais próximos do atual padrão multiplex. 0 livro, que está dividido em três partes, narra a história, desde a infância até a vida adulta, de Joaquín Camino, um homossexual, filho da alta burguesia limenha, que não aceita o silêncio sobre a sua sexualidade, assim como também não compactua com a possibilidade de viver um casamento heterossexual de fachada. Joaquin, 
contrariando o que deseja o seu entorno social, investe politicamente, como argumenta Alós (2013: 353), em uma saída do armário como possibilidade de mudança social.

$\mathrm{Na}$ primeira parte do romance, após um incidente familiar que termina com seu espancamento e a assunção de sua homossexualidade, quando ainda tinha quinze anos, Joaquín rouba uma joia familiar e foge de casa. Após vagar pela cidade, termina entrando em um antigo cinema, em uma sessão para maiores de vinte e um anos, cuja assistência é exclusivamente masculina, onde passava $O$ Último Tango em Paris. Joaquín excitado não só com o erotismo do espaço, mas também com o filme, termina se masturbando sozinho no banheiro. No segundo momento do livro, convidado por uma amiga, Joaquín vai a um cinema, possivelmente multiplex, assistir a um filme de Harrison Ford. Sentados na última fila, Joaquín começa a flertar com outro rapaz e o banheiro do cinema é utilizado para o desejo erótico. Assim nos relata o narrador,

Joaquín miró al chico: le pareció muy atractivo. Segundos después, el chico le devolvió la mirada. Se miraron a los ojos, sin sonreír. Antes que se apagasen las luces, se miraron de nuevo. No bien comenzó la película, el chico se puso de pie, miró a Joaquín, le hizo una seña con la cabeza y salió de la sala. Joaquín sintió un cosquilleo en la espalda. Sabía que no iba a poder resistir la tentación.

—Tengo que darles de comer a los chilenos —le dijo a Alexandra, hablándole al oído. (Bayly 2006: 717)

A diferença entre os dois cinemas frequentados por Joaquín pode ser percebida não só pelo filme exibido, um permitido apenas para maiores de vinte e um anos, outro um blockbuster, mas também pelo público, pelos serviços alimentícios ofertados dentro do cinema e pela localização da sala. Assim, no primeiro, o narrador parece sugerir uma futura especialização do local no gênero pornográfico, o que não impede, entretanto, que práticas eróticas ocorram nos dois espaços.

A partir desses seis textos, pudemos perceber como o espaço físico do cinema, em suas três fases, foi sempre atravessado por usos eróticos. No conto de Capadócio, os personagens experimentam a primeira fase cinematográfica, as pequenas salas de exibição, nos textos de Correas, Donato, Cabrera Infante e Jaime, os personagens vivenciam a 
segunda fase, as grandes salas de cinema, no conto de Bayly, a terceira fase, os cinemas em grandes centros comerciais, com seus combos extragrandes de pipoca e Coca-Cola.

\section{Os palácios cinematográficos}

A transição para o que denominamos "segunda fase do cinema" ocorreu, de acordo com Pena (2013: 59), devido não só ao expressivo aumento de público, o cinema tornou-se um entretenimento massivo, mas também devido ao desenvolvimento tecnológico e a consequente industrialização do cinema, o que demandou a construção de grandes salas de exibição, os palácios cinematográficos, cuja média de assentos variava entre quinhentos e quatro mil lugares. Os palácios cinematográficos, que geralmente ocupavam um prédio inteiro e tinham apenas uma única e grande sala de exibição, representam o auge comercial dos cinemas de rua, assim como também representam o auge arquitetônico e cinematográfico do funcionamento de dispositivos disciplinares, principalmente, de classe, gênero e sexualidade.

A arquitetura grandiosa e a decoração luxuosa desses espaços buscavam não somente equiparar o cinema às outras artes mais tradicionais, como a ópera e o teatro com as suas imponentes salas, como também estavam interessadas em educar e disciplinar os corpos dos espectadores para um novo paradigma de consumo cinematográfico. Os espectadores são interpelados nesses espaços para uma nova forma de assistir ao filme, que passa tanto pelo silêncio, quanto pela imobilidade dos corpos. A nova "situação cinema", ou melhor, a docilização dos corpos para o consumo cinematográfico, foi descrita e reclamada por Reyes na crônica "Las quejas del público", publicada em 23 de dezembro de 1915, no jornal España. Nesta, a partir de queixas feitas por espectadores, recebidas através de cartas, Reyes reclama por silêncio dentro das salas e estabelece que o perfeito espectador de cinema pede silêncio, isolamento e escuridão.

Assim como nas grandes salas de teatro e de ópera, onde a presença nesses lugares era também uma forma de distinção social, as grandes, requintadas e luxuosas salas cinematográficas também representavam um capital simbólico importante para seus frequentadores. Por isso, as antessalas dos cinemas eram socialmente muito importantes, 
para se fazer ver e notar, uma vez que as salas de exibição precisavam da escuridão; diferentemente do teatro, onde a visibilidade da plateia era maior, o que permitia a exibição social dentro da própria sala do espetáculo.

Um outro importante aspecto, sempre retomado romanticamente tanto por historiadores de cinema quanto por cineastas, diz respeito à relação que se estabelecia entre o filme exibido e a arquitetura da sala. Nesse sentido, a partir de Cozarinski (2006: 13), podemos afirmar que os palácios cinematográficos antecipavam também o clima de ilusão, luxo e fantasia que os filmes criavam em torno de si e das suas estrelas. Assim, quando as grandes produtoras se tornaram também donas ou locatárias de algumas salas, a arquitetura desses lugares passou a dialogar mais diretamente com os filmes. Carlos Drummond de Andrade, na crônica "Os cinemas estão acabando", publicada no Jornal do Brasil, em 19 de janeiro de 1984, aborda a relação que existia entre os espectadores e os cinemas de produtoras, e diz:

A gente amava um cinema de bairro pela soma de emoção que ele oferecia, como se o filme tivesse sido elaborado ali e então a lembrança do artista ficava trançada com o nome da casa. Mesmo porque, em geral, certos filmes, de certas marcas, só eram exibidos em tal cinema [...] os cinemas, presos a contratos especiais, exibiam só a produção de cada marca. Daí surgiu a forte relação cinemaespectador, que imperou dezenas de anos para também se diluir. (Drummond de Andrade 1984: 29)

Enquanto nos Estados Unidos as grandes salas foram construídas majoritariamente entre 1910 e 1930, no Brasil e na Argentina, por exemplo, datam, principalmente, do período entre 1920 e 1950. No entanto, ainda que os palácios cinematográficos tenham se espalhado por diferentes regiões das grandes cidades; a área da Cinelândia, no Brasil, assim como a região de Lavalle, na Argentina, representaram projetos grandiosos tanto para a cinematografia, quanto para a arquitetura e o urbanismo dos dois países. A Cinelândia, de acordo com Bessa (2013: 102), foi construída pensando em ser a Times Square brasileira, enquanto a região da rua Lavalle, segundo Cozarinski (2006: 34), foi planejada para ser a Broadway portenha. Por conta disso, a arquitetura desses lugares simulava os grandes 
prédios e cinemas de Nova York; o que, consequentemente, influenciou na construção de um entorno urbano também grandioso.

Muitos desses cinemas, como afirma Bessa (2013: 21), chegaram ao ponto de exigirem trajes obrigatórios para o acesso às salas. Por conta disso, a escolha da sala de cinema era também uma forma de distinção social, uma vez que, para além da exigência de uma vestimenta "adequada", aumentava-se também o preço do ingresso. Nesse sentido, podemos conjecturar que essas duas regiões funcionaram como protótipos dos futuros shopping centers, ou seja, eram áreas luxuosas, assépticas e seguras para o consumo burguês. Assim, se o shopping center é um simulacro da cidade de serviços, como argumenta Sarlo (1997: 14), as áreas da Cinelândia e de Lavalle foram, sem dúvida, modelos para um futuro que se aproximava.

O cinema sonoro e o ar-condicionado, que posteriormente forçaram a reforma das grandes salas, foram duas mudanças que fizeram o público cinematográfico crescer e que garantiram também uma presença mais constante nesses espaços, já que, durante o verão, conforme Bessa (2013: 125), esses recintos costumavam ter uma queda de público devido ao calor e ao abafamento no interior das salas. Importante salientar, seguindo a Cozarinski (2006: 22), que o cinema sonoro significou mudanças distintas para os diferentes países. Na Argentina e no Brasil, por exemplo, significou não só o fim da música ao vivo, mas também o desemprego de uma significativa quantidade de músicos, enquanto no Japão significou o desaparecimento dos benshis, narradores-atores que contavam dramaticamente a ação dos filmes mudos, cuja quantidade de fãs muitas vezes superava a das estrelas cinematográficas.

Apesar das inovações tecnológicas e narrativas, os anos 60 e 70 significaram para os cinemas de rua uma vertiginosa queda de público. 0 apelo da arquitetura cinematográfica já não era mais garantia de público, as salas envelheciam e as reformas se tornaram cada vez mais custosas. Além disso, surgiram os cineclubes, com arquitetura simples e modernista, que passaram a atrair um grande público; superando, rapidamente, de acordo com Bessa (2013: 178), os palácios cinematográficos em contagem de público e de salas.

Os novos hábitos cinematográficos, segundo Cozarinski (2006: 53), decretaram 
obsoletas as grandes salas. Entramos, assim, em uma "terceira fase" do cinema, que ficou marcada pelo abandono dos cinemas de rua, pela migração de salas para os shopping centers e pelo surgimento de cinemas pornôs e de cineclubes. Nesse sentido, uma série de outros fatores também contribuíram para o desaparecimento dos cinemas de rua: a televisão, o videocassete, o abandono e a especulação imobiliária dos grandes centros urbanos, etc.

De acordo com Cozarinski (2006: 24), o aparecimento da televisão, ainda nos anos 50, e sua expressiva e rápida popularização, foi a primeira causa da queda de público; os cinemas tentaram contra-atacar com telas maiores, mas não obtiveram bons resultados. A indústria televisiva crescia, enquanto a cinematográfica entrava em crise. Em seguida, vieram os videocassetes, era o aprofundamento da reprodutibilidade da técnica cinematográfica, que de uma vez só sepultava a aura cinematográfica, os espaços de exibição e o erotismo difuso das salas.

Drummond, na crônica de 1984, também nos relata o desaparecimento de alguns cinemas de rua do Rio de Janeiro, ao mesmo tempo em que especula as possíveis causas. A primeira delas seria a massificação da televisão, mas contribuíram também a violência urbana e o custo financeiro dos cinemas. Seguindo a crônica, o "motivo dos motivos" é que "tudo passa". Assim sendo, o tempo do cinema, enquanto principal forma de lazer e diversão, havia também passado. Segundo Drummond (1984), da mesma forma que uma criança se cansa de um brinquedo, os espectadores também cansaram do cinema e das suas grandes salas, consequentemente, o futuro desses espaços agora seria decidido pela especulação imobiliária e pelo mercado financeiro. Nesse mesmo sentido, resume Juan José Sebreli,

En la segunda mitad del siglo, el cine perdió su halito mágico y sobrevivió como un espectáculo más entre otros, o en un número limitado de filmes fue un arte para un minoritario publico adicto al cine de autor o independiente. Una tras otra las salas de barrio - y luego las del centro - se transformaron en templos evangélicos, playas de estacionamiento o mercado de pulgas. [...] La causa más notoria, pero no la única, de esta decadencia fue la aparición de la televisión y su complemento, el video. (Sebreli 2011: 461) 
Podemos afirmar, então, que o progressivo abandono do centro das grandes cidades, que acarretou no aumento da violência urbana, na especulação imobiliária e no deslocamento de lojas e lugares de entretenimento para os novos shopping centers, foram também importantes fatores para o desmoronamento da cadeia cinematográfica de rua desses dois países. Essas grandes salas, agora entendidas como grandes "elefantes brancos", inicialmente, tentaram sobreviver fragmentando as salas de exibição. Segundo Cozarinski (2006: 25), esse fenômeno, acentuou-se nos anos 80. Nesse mesmo sentido, Charly Cruz, personagem de Bolaño (2004), diz:

Las únicas salas de cine que cumplían una función [...] eran las viejas, ¿las recuerdas?, esos teatros enormes que cuando se apagaban las luces a uno se le encogía el corazón. Esas salas estaban bien, eran los verdaderos cines, lo más parecido a una iglesia, techos altísimos, grandes cortinas rojo granate, columnas, pasillos con viejas alfombras desgastadas, palcos, localidades de platea y galería o gallinero, edificios construidos en los años en los que el cine todavía era una experiencia religiosa, cotidiana y sin embargo religiosa, y que poco a poco fueron demolidos para edificar bancos o supermercados o multicines. Hoy [...] apenas sobreviven unos pocos, hoy todos los cines son multicines, con pantallas pequeñas, espacio reducido, butacas comodísimas. En el espacio de una vieja sala de verdad caben siete salas reducidas de un multicine. 0 diez. 0 quince, depende. Y ya no hay experiencia abismal. (Bolaño 2004: 397)

Os anos 70 e 80 significaram, portanto, o fechamento de quase todos os palácios cinematográficos. A maior parte desses espaços foi destruída para dar lugar a novos empreendimentos comerciais; alguns mantiveram a estrutura física com novos e distintos usos, especialmente cultos evangélicos e bingos; com raríssimas exceções alguns se mantiveram como cinemas geminados ou não. Cozarisnky (2006: 34) diz que a antiga Broadway portenha agora é ocupada por bingos, cultos evangélicos e outlets de roupas; enquanto isso a antiga Times Square brasileira é agora ocupada por cultos evangélicos e fastfoods.

No conto "A última sessão" (2015), o narrador de Marcelino Freire nos oferece, a partir da história de um "velho usuário", um belo testemunho da transformação dos antigos 
palácios em igrejas evangélicas. Nessa última sessão, o "Velho", depois de sair do hospital, onde tinha ficado um ano internado por conta de uma queda, volta ao antigo cinema, que funcionava como pornô, o Cine Palácio, que ele havia transformado em casa devido às dificuldades financeiras, e "esclerosado, debilitado" não percebe que o "escuro mágico" do antigo cinema pornô era agora uma igreja evangélica, cuja iluminação atirava "luz celeste em todo mundo".

A primeira coisa que o Velho faz, ao entrar no espaço, é procurar por sua melhor amiga Zélia Suave e insiste em perguntar a um dos crentes onde ela está. Zélia e o Velho ficaram amigos dentro do cinema pornô; nos intervalos dos programas, quando Zélia sentava-se junto a ele e trocavam palavras sinceras. Envolvido com suas lembranças, o Velho começa a se incomodar com os gritos, que não eram mais gemidos e sussurros, mas berros que pediam por perdão, agradeciam graças alcançadas e louvavam. 0 Velho percebe que aquele não é mais o seu lugar, e sem forças vai caindo no chão até morrer, enquanto espera começar a próxima sessão.

De forma semelhante, na crônica "El mantra final de la Marie Roxette o las melenas oxigenadas de la Aldea Gay" (2016), Alejandro Modarelli nos conta que ao também retornar a um antigo cinema pornô, depois de uma semana sem poder ir devido a uma angina, encontra-o fechado, provavelmente se transformaria em mais um supermercado. Nas portas lacradas do extinto cinema, a respeitada travesti Marie Roxette chorava o seu exílio.

A migração das salas para o interior dos shopping centers sepultou quase todos os cinemas de rua. 0 shopping realizou parte da utopia modernista, não só por afastar a rua e os espaços escuros da vida burguesa, mas, principalmente, conforme Sarlo (1997: 15), pela deriva iluminada e organizada que impõe, pelo panóptico que instala e pela produção de corpos e hábitos dóceis. O labirinto da cidade transforma-se em uma cápsula, onde é impossível perder-se. Dentro do shopping, a arquitetura dos cinemas perde importância. As salas passam a ser padronizadas em uma estética reta, limpa e fria.

O fenômeno de gentrificação do espaço público pode trazer novamente os cinemas para as ruas, entretanto, essa reterritorialização do cinema, através de um mercado que ocupa e privatiza determinados espaços públicos, não recupera um uso que pensa o espaço 
de forma mais democrática, ao contrário, esses espaços passam a funcionar quase sempre como grandes shoppings a céu aberto, onde até mesmo o mobiliário e a decoração do entorno simulam os grandes centros comerciais. Como explica Cortés (2008: 10), o espaço público, antes de ser pensado como lugar de encontro, é planejado como lugar de consumo. Há, dessa forma, uma reapropriação do espaço que visa um controle maior sobre o espaço público e uma docilização e/ou exclusão dos corpos que deverão circular nesse novo ambiente.

Entretanto, enquanto a maior parte dos cinemas de rua migrava para os shopping centers, algumas poucas grandes salas se especializaram em conteúdo pornográfico. Como já dissemos, mais do que um desejo de sobrevivência desses espaços, houve uma verdadeira ocupação que resistiu não só à violência policial, mas também ao próprio mercado. Ainda que a maior parte dos cinemas pornôs tenha surgido durante a terceira fase, com a crise da cadeia cinematográfica tradicional e o abandono dos centros urbanos, especialmente nos anos 70 e 80, época áurea do cinema pornô de rua, há relatos de cinemas eróticos ainda nos anos 50 em São Paulo, Buenos Aires e Cuba, segundo Sester (2014: 4), Cozarinski (2006: 69) e Freixas (2000: 219).

A exibição, nos anos 70, em meio a batalhas judiciais, de alguns filmes, como $O$ Último Tango em Paris (1972), Império dos Sentidos (1976) e Calígula (1979), e de alguns gêneros cinematográficos, como a pornochanchada brasileira, não só diluíram as fronteiras entre filme de arte, filme comercial e filme pornográfico, como também favoreceram a transformação de alguns desses espaços em cinemas pornôs, conforme Pena (2013: 81). Na Argentina, a proibição da prostituição e o fechamento de bordéis colaboraram também nessa transição.

Na novela No se lo digas a nadie (Bayly 2006: 332), a percepção de Joaquín sobre o filme de Bernardo Bertolucci como erótico, além da localização do cinema em uma região central e de um público exclusivamente masculino, podem ser vistos como indícios da especialização do cine Colón no gênero pornográfico. Um outro texto que também mostra um personagem que entende o filme de Bertolucci como erótico é o conto " $\mathrm{O}$ corpo", do livro A Via Crucis do Corpo (1998), de Clarice Lispector. Neste, a narradora nos diz que o 
personagem Xavier não só entendeu o filme como erótico, como também ficou terrivelmente excitado.

Xavier era um homem truculento e sanguíneo. Muito forte esse homem. Adorava tango. Foi ver 0 Último Tango em Paris e excitou-se terrivelmente. Não compreendeu o filme: achava que se tratava de filme de sexo. Não descobriu que aquela era a história de um homem desesperado. (Lispector 1998: 21)

No início dos anos 80, as dobradinhas entre filmes de lutas marciais e filmes softcore, onde as relações sexuais eram apenas simuladas e não havia exibição de órgãos genitais, também atraíram um público razoável aos cinemas de rua. No conto "Nas matinês do Cinema Íris" (1986), o narrador de Aguinaldo Silva, em sua primeira ida a um cinema pornô, assim descreve os filmes exibidos: "Quando eu cheguei lá naquela noite, o cartaz à entrada do Cinema Íris anunciava Kung Fu Contra os Filhos do Karatê e Eu Dou o que Ela Gosta, em sessão dupla" (Silva 1986: 17).

Entretanto, segundo a crônica de Lemebel (2001), nessas sessões, ninguém estava muito interessado em assistir às coreografias de Bruce Lee. 0 interesse dos espectadores estava especialmente voltado para o filme que era produzido pela plateia. Nesse sentido, 0 cronista nos diz que nem a Metro Golden Mayer e nem a Columbia Pictures teriam imaginado que Bruce Lee "sirviera para controlar la explosión demográfica a tan bajo costo" (Lemebel 2001: 17). A novela de Capucho (1999:10) também narra, de forma parecida, onde era verdadeiramente produzido o filme: "O filme principal não se passa na tela, mas na plateia".

Com o tempo, o público, cansado do erotismo dos filmes soft, passou a demandar filmes hardcore, onde o sexo não era simulado e havia a exibição completa dos corpos e das relações sexuais. Como afirma Pena (2013: 81), a "ousadia implícita não era mais suficiente, era preciso trazer à cena o que ficava atrás das cortinas, nas silhuetas". No Brasil, o filme Coisas Eróticas (1981) marcou, conforme Abreu (1994: 51), a passagem do soft-core para o hardcore. Dois anos depois do filme, dos 105 filmes produzidos no Brasil, 69 eram de sexo explícito. 
Nesse momento, os cinemas deixaram de ser apenas um local de exibição de filmes, onde alguns usos eróticos eram possíveis, para se tornarem, à despeito dos seus donos e administradores, lugares onde as práticas sexuais faziam parte da "situação cinema". Nos cinemas pornôs, portanto, os espectadores não só "assistiam" a filmes que não passavam na televisão, como também experimentavam práticas sexualmente dissidentes.

De acordo com Câmara Vale (2000: 77), a especialização de salas de exibição em filmes pornográficos delimitou uma nova dinâmica na distribuição dos poderes e prazeres, uma vez que, com a movimentação da plateia, o cinema passa a ser um local de maior disponibilidade erótica. Dessa maneira, a inércia e a imobilidade do espectador, características do dispositivo cinema, são abandonadas, ou pelo menos relativizadas, em função dos desejos eróticos dos frequentadores.

A movimentação da plateia dentro dos cinemões é narrada, nos textos literários, ora como dança, ora como experimentações de devires animais, ora como caçada/safari. Nos pequenos trechos abaixo, do conto de Aguinaldo Silva (1986), da crônica de Naty Menstrual (2009) e do conto de Susy Shock (2013), podemos perceber como são descritos esses deslocamentos.

Quem o vê pelo lado de fora, em dias de sessões contínuas, imagina uma colmeia [...] os espectadores se movimentam num vaivém constante. (Silva 1986: 16)

En la oscuridad de la sala, después de acostumbrar la vista como los gatos, empecé a ver decenas de tipos que andaban dando vueltas por todos lados. Eran tipos y tipos y más tipos, como un grupo de experimentados cazadores. (Menstrual 2009)

la entrada que me habilita el paso en este cine porno de los santos ortos para bailar la conga de la promíscua sola o la promíscua toda, pero nunca más la promíscua vos, que ya te fuiste. (Shock 2013: 19)

Nesse sentido, se entendemos que o conteúdo ou a forma de expressão de cada filme, como sugere Guattari (1984), visa, fundamentalmente, a produção de um certo tipo de performance cinematográfica dos espectadores, podemos dizer, então, que o cinema e os 
filmes pornográficos profanam o tradicional modo de recepção cinematográfica, uma vez que os espectadores colaboram com a recepção a partir dos prazeres e dos desejos experimentados nos próprios corpos. Diante da tradicional "situação cinema", são corpos indisciplinados que reagem contrariamente às interpelações de imobilidade, isolamento e silêncio.

Essa movimentação dos espectadores dentro do cinema, que funciona como táticas e códigos de aproximação, ficou conhecida tanto no Brasil, como na Argentina e em Cuba como "fazer o xadrez". Segundo Peralta (2013: 447), ao fazer o xadrez, as pessoas mudam de lugar em busca de alguém que lhe interesse e que lhe corresponda, para em seguida estabelecer contatos eróticos. Essa dança erótica, sobre a qual já falamos a partir de Correas (1959), é feita tanto pelos usuários do cinema, como podemos perceber abaixo através da novela de Cabrera Infante (2005), quanto por aqueles que trabalham nesses locais com a prostituição.

Yo había aprendido a medir térmicamente la proximidad de otro cuerpo en el cine con precisión casi científica. Me ayudaba que ninguna muchacha llevaba manga larga y la carne estaba desnuda, irradiando calor erótico hasta mis brazos como antenas vibrátiles [...] El próximo movimiento mío en este ajedrez del amor sería ponerle una mano en un muslo: peón del rey a dama. (Cabrera Infante 2005: 57)

No conto "Paraíba", Damata (1975) aponta para um deslocamento de determinados corpos da deriva urbana da rua para uma deriva privatizada do cinema, cuja principal causa é a perseguição do Estado a corpos e desejos dissidentes. Assim, além de serem espaços eróticos, os cinemas pornôs são também locais de resistência e de sobrevivência erótica. Como poetiza Modarelli (2016: 103), "Nosotras somos cóndoras de vuelo mariposa, y nuestro cuartel es un cine $\mathrm{X}$ de butacas quebradas; la esquina noctámbula donde el chongo malo, pura verga, afila la navaja". Segundo Green (2000: 163), a dificuldade para ter acesso a quartos por hora e a possibilidade de prisão por atentado ao pudor foram motivações que levaram os dissidentes a uma maior ocupação dos espaços cinematográficos para práticas sexuais. Nesse mesmo sentido, de acordo com Cozarinski (2006: 79), a proibição tanto da 
prostituição, quanto de bordéis, na Argentina, entre os anos 50 e 60, levou a um maior deslocamento desses sujeitos para dentro dos cinemas.

A crise e o consequente desaparecimento de alguns cinemas pornôs não se relacionam com o abandono dos centros urbanos; esse foi um fator que favoreceu o aparecimento dessas salas. Entretanto, podemos dizer que os avanços tecnológicos, ao mesmo tempo em que significaram um boom na produção de filmes eróticos, foram também responsáveis pelo fechamento de algumas dessas salas pornográficas, uma vez que as facilidades tecnológicas transformaram o consumo público de filmes pornográficos em matéria de fruição privada.

Além disso, o mercado do cinema pornô enfrentou, entre os anos 80 e 90, duas crises que lhe reduziram o público e que levou ao fechamento de mais alguns desses cinemas. A primeira se relaciona com a epidemia de HIV, que teria, segundo Perlongher (2008b: 20), cumprido um importante papel em uma nova onda conservadora que se abateu, principalmente, sobre os dissidentes de gênero e sexualidade. Nesse momento, não somente os cinemas foram fechados, mas também outros espaços de encontro e sociabilidade erótica. Podemos entender o HIV, portanto, não só como uma enfermidade que ataca o sistema imunológico, mas também como um dispositivo biopolítico de controle e normalização dos corpos.

Assim sendo, Cortés (2008: 168) diz que esses espaços, essas arquiteturas do desejo, acabaram se convertendo, entre meados dos anos 80 e 90, em arquiteturas do medo, em lugares de desolação e perda. Desse modo, concomitantemente à intervenção dos Estados, houve um gradual abandono desses espaços. No livro de contos e memórias Trem Fantasma (2000), Carlos Hee relata as consequências da pandemia nos circuitos eróticos brasileiros. Segundo o narrador "era o fim de uma era", na qual "nenhum lugar estava imune de ser transformado em ponto de encontros sexuais" (HEE 2000: 91).

No livro El mendigo chupapijas (2005), o narrador de Pablo Pérez relata o fechamento de oito cinemas pornôs em Buenos Aires, em apenas uma semana. De acordo com o mesmo (2005: 18), as causas são morais, entretanto, a partir da narrativa, podemos inferir que o acirramento do conservadorismo, que leva ao fechamento de locais de pegação 
e de sociabilidade dissidente em Buenos Aires, se aprofunda na crise do HIV/Aids. Como constata Perlongher (2008: 86), se não desaparece a união de corpos do mesmo sexo, desaparece, pelo menos, o apogeu, a festividade, a promiscuidade, "a festa da orgia homossexual". A epidemia do HIV/Aids, dessa forma, eleva à máxima potência a vigilância e o controle das sexualidades.

Os médicos, como não conseguiam mais recomendar a castidade, passaram a advogar não só pelo fechamento desses espaços, assim como por uma sexualidade limpa, sem riscos, desinfetada, transparente, controlada e monogâmica. Nesse sentido, a normalização das homossexualidades, ou melhor, a agenda política de respeitabilidade de parte majoritária da militância lgbt, também como estratégia para se defender das violências e dos sonhos de extermínio decorrentes da pandemia do HIV/Aids, passa a entender os espaços eróticos de pegação (banheiros, parques, cinemas, etc.) como decadentes, inseguros e degradantes. Por conseguinte, seus usuários passam a ser estigmatizados como promíscuos, degenerados ou problemáticos em relação à homossexualidade. Nessa mesma perspectiva, os cinemas pornôs passaram a ocupar a mais baixa hierarquia no mercado de consumo erótico.

\section{Fechando as cortinas}

Uma outra questão que tem recentemente corroborado com o fechamento dos cinemas pornôs são as políticas de segurança pública e de gentrificação de algumas áreas urbanas. Como já dissemos, as políticas de aburguesamento do espaço público não só afastam dos locais os antigos frequentadores, como também respondem aos interesses da especulação imobiliária e desconsideram o patrimônio imaterial desses espaços cinematográficos.

Nesse sentido, conforme Teixeira (2013: 108), a presença de estabelecimentos pornográficos causa uma certa "ansiedade", tanto pela percepção de decadência, perigo e medo da dissidência sexual, como pela percepção burguesa de cidade correta, entendida como "paisagens discretas, distinção clara entre público e privado, classes, raças e sexualidades homogêneas, controle social". Essa percepção leva a uma visão urbana 
contrária às necessidades e direitos dos grupos urbanos que não comungam com a mesma visão de cidade e de sexualidade, que teriam "nos estabelecimentos pornográficos, elementos constitutivos de comunidade, cultura e identidade".

Estabelece-se, assim, em torno dos cinemas pornográficos uma política de silêncio, onde estes passam a ser lembrados apenas quando interessam aos projetos de revitalização e de especulação imobiliária. Nesse sentido, a partir de informações cedidas pela Agência Nacional de Cinema (ANCINE), do Ministério da Cultura do Brasil, assim como pelo Instituto Nacional de Cine y Artes Visuales (INCAA), do Ministério da Cultura da Argentina, percebemos que os cinemas pornográficos brasileiros e argentinos não são entendidos como cinemas, e, por isso, tais espaços estão impossibilitados de acessarem às leis de incentivo e/ou fomento destinadas não somente aos cinemas de rua, mas aos cinemas em geral. Os cinemas pornográficos estão no armário, não por estarem ocultos nas ruas, mas por não serem nem mesmo considerados cinemas.

\section{NOTA}

\footnotetext{
${ }^{1}$ Chongo está associado à virilidade masculina. Atualmente, como explica Horácio Sívori (1994: 69), refere-se a todo homem de aparência masculina "natural" ou "não produzida", independentemente da sua prática sexual.
} 


\section{Bibliografia}

Abreu, Nuno César (1994), O Olhar Pornô. A Representação do Obsceno, São Paulo, Universidade de São Paulo.

Adorno, Theodor/ Max Horkheimer (1985), A Dialética do Esclarecimento, tradução de Guido Antonio de Almeida, Rio de Janeiro, Zahar.

Alós, Anselmo Peres (2013). "Não contar a ninguém ou contar a todo mundo? Colapsos da masculinidade em No se lo digas a nadie", Revista Estudos Feministas, 343-370.

Asís, Jorge (1982), La Calle de los Caballos Muertos, Buenos Aires, Legasa.

Barthes, Roland (2009). "Salir del cine", in Lo Obvio y lo Obtuso. Imágenes, Gestos, Voces, tradução de Fernández Medrano, Buenos Aires, Paidós.

Bayly, Jaime (2006), No se lo Digas a Nadie, Barcelona, Seix Barral.

Bessa, Marcia (2013), Entre Achados e Perdidos: Colecionando Memórias dos Palácios Cinematográficos da Cidade do Rio de Janeiro, Rio de Janeiro, Universidade Federal do Rio de Janeiro.

Bolaño, Roberto (2004), 2666, Barcelona, Anagrama.

Cabrera Infante, Guillermo (2005), La Habana para un Infante Difunto, Barcelona, Seix Barral.

Câmara Vale, Alexandre (2000), No Escurinho do Cinema. Cenas de um Público Implícito, São Paulo, Annablume.

Capucho, Luís (1999), Cinema Orly, Rio de Janeiro, Interlúdio.

Correas, Carlos (1959), “La narración de la historia”, Buenos Aires, Revista Centro.

Cortés, José Miguel (2008), Políticas do Espaço. Arquitetura, Gênero e Controle Social, São Paulo, Senac. 
Costa, Flávia Cesarino (2005), O Primeiro Cinema. Espetáculo, Narração, Domesticação, Rio de Janeiro, Azougue.

Cozarinsky, Edgardo (2006), Palacios Plebeyos, Buenos Aires, Sudamericana.

Damata, Gasparino (1967), Histórias do Amor Maldito, Rio de Janeiro, Record.

-- (1975), Os Solteirões, Rio de Janeiro, Pallas.

Donato, Mario (2001), Presença de Anita, Rio de Janeiro, Objetiva.

Drummond de Andrade, Carlos (1984), "Os cinemas estão acabando”, Jornal do Brasil, 19 jan, 29.

Freire, Marcelino (2015), Amar É Crime, Rio de Janeiro, Record.

Freixas, Ramon / Joan Bassa (2000), El Sexo en el Cine y el Cine de Sexo, Barcelona, Paidós.

Green, James (2000). Além do Carnaval. A Homossexualidade Masculina no Brasil do século $X X$, São Paulo, UNESP.

Guattari, Felix (1984). “O divã do pobre”, in Psicanálise e Cinema, Lisboa, Relógio d' Água.

Hee, Carlos (2002), Trem Fantasma, São Paulo, Mandarim.

Jaime, Jorge (1953), Homossexualismo Masculino, Rio de Janeiro, O Construtor.

Lauretis, Teresa (1994), "A tecnologia de gênero", in Tendências e Impasses. O Feminismo como Crítica da Cultura, Rio de Janeiro, Rocco.

Lemebel, Pedro (2001), La Esquina es mi Corazón, Santiago, Seix Barral.

Lispector, Clarice (1998), A Via Crucis do Corpo, Rio de Janeiro, Rocco.

Maluco, Capadócio (1914), O Menino do Gouveia, Rio de Janeiro, Cupido \& Companhia.

Menstrual, Naty (2009), “Corazón de cine porno”, <https://bit.ly/2kQWOrx> (último acesso em 04/07/2019).

Modarelli, Alejandro (2016), La Noche del Mundo. Brumario de Maricas, Buenos Aires, Mansalva. 
Pena, João Soares (2013), Espaços de Excitação. Cines Pornôs no Centro de Salvador, Salvador, Universidade Federal da Bahia.

Peralta, Jorge Luis (2013), Espacios Homoeróticos en la Literatura Argentina (1914-1964), Barcelona, Universitat Autonoma de Barcelona.

Pérez, Pablo (2005), El Mendigo Chupapijas, Buenos Aires, Mansalva.

Perlongher, Néstor (2008), Prosa Plebeya, Buenos Aires, Colihue.

-- (2008b), O Negócio do Michê. A Prostituição Viril em São Paulo, São Paulo, Perseu Abramo.

Preciado, Paul B (2010), Pornotopía. Arquitectura y Sexualidad en Playboy durante la Guerra Fría, Barcelona, Anagrama.

Reyes, Alfonso (1995), Obras Completas de Alfonso Reyes. Volume IV, Ciudad de México, Fondo de Cultura Económica.

Sarlo, Beatriz (1997), Cenas da Vida Pós-moderna. Intelectuais, Arte e Videocultura na Argentina, tradução de Sérgio Alcides, Rio de Janeiro, Editora UFRJ.

Sebreli, Juan José (2011), Buenos Aires, Vida Cotidiana y Alienación. Buenos Aires, Sudamericana.

Sester, Eros (2014), “Em São Paulo a gente nunca sabe se neblina é poluição - Notas sobre (auto)etnografia em um cinemão paulistano", <https://bit.ly/2HmYmlI> (último acesso 04/07/2019).

Shock, Susy (2013), Relatos en Canecalón, Buenos Aires, Nuevos Tiempos.

Silva, Aguinaldo (1986), Memórias da Guerra, Rio de Janeiro, Record.

Sívori, Horácio (1994), Locas, Chongos y Gays. Sociabilidad Homosexual Masculina durante la Década del 1990, Buenos Aires, Antropofagia.

Teixeira, Marcelo (2013), Presença Incômoda. Corpos Dissidentes na Cidade Modernista, Brasília, Universidade de Brasília.

Viana, Antônio Carlos (2001), Cine Privê, São Paulo, Companhia das Letras. 
Helder Thiago Maia

Helder Thiago Maia é Doutor em Literatura Comparada (UFF, 2018), Pós-Doutorando, com bolsa FAPESP n. 2018/19521-4, na Universidade de São Paulo (USP). É pesquisador do NuCuS, da Universidade Federal da Bahia (UFBA), e pesquisador associado da Red LIESS, da Espanha. É editor da Revista Periódicus (UFBA) e autor dos livros $O$ devir darkroom e a literatura hispano-americana (2014) e Cine[mão]: espaços e subjetividades darkroom (2018). 